Annales Geophysicae (2001) 19: 245-256 (C) European Geophysical Society 2001

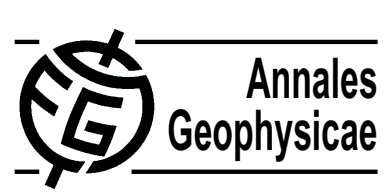

\title{
Modeling the impact of atmospheric and terrestrial inputs on the Black Sea coastal dynamics
}

\author{
V. H. Kourafalou ${ }^{1}$ and E. V. Stanev ${ }^{2}$ \\ ${ }^{1}$ National Center for Marine Research, Institute of Oceanography, Athens, Greece \\ ${ }^{2}$ University of Sofia, Department of Meteorology and Geophysics, Sofia, Bulgaria
}

Received: 31 March 2000 - Revised: 21 November 2000 - Accepted: 18 December 2000

\begin{abstract}
The dynamics on the North Western Shelf area of the Black Sea are examined, with an emphasis on the circulation induced by buoyancy due to the land drained fresh waters and by the interaction with the atmosphere, notably wind stress. A three-dimensional, multi-layer hydrodynamic model is employed with realistic topography and parameterisation of river plume physics. We focus on the seasonal patterns of transport of the river induced low-salinity waters within the Coastal Low Salinity Band and the conditions that influence their removal toward the shelf interior.

The numerical simulations show that coastal circulation is greatly influenced by river runoff and especially in the case of the Danube, which is excessively high with monthly averaged values ranging from 5000 to $10000 \mathrm{~m}^{3} / \mathrm{s}$. A significant contribution of runoff comes from the neighboring rivers. At the same time, the NorthWestern Shelf is quite broad, so that the coastal dynamics are largely sheltered from the conditions in the deeper sea. Buoyancy due to river runoff thus dominates, creating a southward coastal current that is the predominant pathway for the land-drained inputs. As in all shelf areas, wind stress is a major circulation forcing mechanism and it modifies the buoyancy induced flow. It is shown that the seasonal variability in river runoff and wind stress, in combination with the shelf topography, determines the different pathways for the terrestrial inputs.

Implications on the overall basin circulation are drawn, as the availability of low-salinity waters of river origin affects the upper Black Sea layer. Consequently, the formation of distinct water masses (such as the Cold Intermediate Layer) and the properties of the outflow toward the Mediterranean are also influenced.
\end{abstract}

Key words. Oceanography: general (continental shelf processes; numerical modeling) - Oceanography: physical (air-

Correspondence to: V. Kourafalou (villy@ fl.ncmr.gr) sea interactions)

\section{Introduction}

The Black Sea (Fig. 1) is an often forgotten component of the Mediterranean Sea system, mainly due to its particular dynamic characteristics that are dictated by the delicate connection with the rest of the basin. The link is established through the narrow Strait of Bosphorous $(\sim 1 \mathrm{~km})$, which imposes a strong hydraulic control on the inflow of salty Eastern Mediterranean water and outflow of fresher Black Sea water. The vast area of the Black Sea (over $4 \cdot 10^{5} \mathrm{~km}^{2}$ ) and the restricted water exchange at Bosphorous result in unique hydrodynamic and biogeochemical conditions in the basin. The most pronounced characteristic in the Black Sea hydrodynamical structure is the remarkable stability in stratification. A thin upper layer with low-salinity (generally not exceeding $\sim 18 \mathrm{psu}$ ) is superimposed on the Cold Intermediate Layer (CIL), while the greatest part of the water column is occupied by a deep-water mass. It is well established by now that the stable stratification is largely due to river runoff, which provides a continuous source of freshwater, diluting the upper basin layers and overwhelming the supply of salt through Bosphorous. One of the direct consequences of restricted mixing between the brackish surface layers and the deeper waters is the prevailing anoxic conditions, which make the Black Sea the world's largest anoxic basin.

The majority of freshwater discharge takes place on the North Western Shelf (NWS), which occupies most of the western Black Sea (taken here as west of the narrowest width of about $250 \mathrm{~km}$, between the Crimea peninsula and the Turkish coast, see Fig. 1). The major rivers are the Danube, Dnestr, Bug and Dnepr. They have strong flow rates, especially the Danube, which is among the largest world rivers 


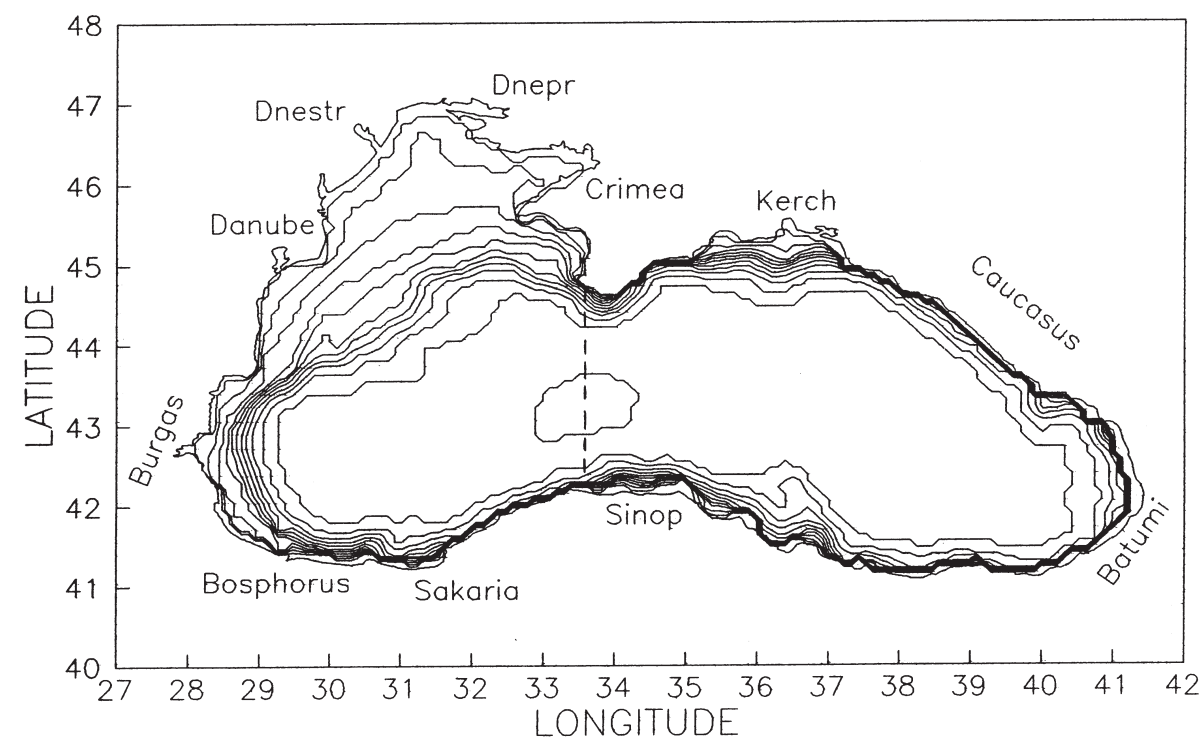

Fig. 1. The Black Sea topography, printed isobaths are: 10, 20, 40, 60, $80,120,210,350,580,990,1640$ and $2250 \mathrm{~m}$ (from Stanev et al., 1996). The dashed line is at the open boundary of the model domain. and the strongest single source of freshwater for the Mediterranean Sea. A number of studies, especially within the framework of large international efforts, such as EROS2000 and EROS21, demonstrated that the low salinity waters and associated sediments, nutrients and pollutants that originate from the Danube runoff have a significant impact in the hydrodynamic and biogeochemical processes of the western Black Sea, while governing the shelf to open sea exchanges in the region (Stanev et al., 2000). Previous studies have also shown that river runoff has a profound influence on the formation of CIL. As discussed in Stanev at al. (1995) and Oguz and Malanotte-Rizzoli (1996), the formation of dense water, which takes place on the NWS, is greatly influenced by the interannual variability in river runoff, particularly in the case of the Danube. The riverine input has a counter-effect on the dense water formation, as it prevents the cold waters (due to intense winter cooling of the shallow water column) from becoming very dense. Consequently, years with strong runoff are characterised with low contribution to the CIL from the shelf. Furthermore, changes in riverine input may have important implications for the hydrodynamical characteristics of the Eastern Mediterranean. Recent climatological changes documented with comprehensive observations (Roether et al., 1996) show a significant drop in the salinity of the Eastern Mediterranean deep waters, while establishing the contribution of Aegean waters in their formation. Since the most direct influence of the Black Sea outflow is in the Aegean Sea, it is easily detected that the reduction in local river runoff that has taken place in the last couple of decades could be one of the key factors in the climatic Eastern Mediterranean change. At the moment, this is speculation that needs detailed studies, preferably including a study area with a coupled Black Sea - Sea of Marmara - Aegean Sea system. During shorter time scales, there is also evidence of the strong influence of low-salinity Black Sea waters in the Aegean Sea circulation, as presented in data by Zodiatis (1994). Similar implications can be drawn for the biogeochemistry. For instance, effects of the Chernobyl nuclear power plant accident (April 1986) carried in the Black Sea through the river Dnepr can be traced in the Aegean Sea, as shown in measurements of radionuclides by Polikarpov et al. (1991).

Several recent modelling studies have elucidated the interannual and seasonal variability of the general circulation (Oguz et al., 1995; Stanev et al., 1995, 1996; Oguz and Malanotte-Rizzoli, 1996). The coastal dynamics on the NWS have received less attention, although the shelf contribution on distinct general circulation features has been shown by Rachev and Stanev (1997), in terms of causing eddy dissipation and by Oguz et al. (1995), in terms of maintaining the basin-wide cyclonic circulation. There have been no systematic theoretical studies on the river plume dynamics in the Black Sea, though some analyses have been done based on earlier observations. Previous model studies (such as Ivanov et al., 1996; Mikhailova and Shapiro, 1997) have mainly used river input as an important agent in the Black Sea water budget, rather than studying the development and evolution of the river plumes.

We present here a study of two of the major mechanisms that force circulation on the shelf, namely buoyancy due to river runoff and wind stress. The objective of the study is to provide a comprehensive, three-dimensional, multilayer model of the NWS with detailed incorporation of plume dynamics and simulations that elucidate the interplay between buoyancy and wind stress in controlling the spreading of the riverine waters. We view this effort as a first step toward the understanding of the underlying processes in order to expand to a coupled physical and biogeochemical model of the NWS in the future. 


\section{Model description}

The model is based on the three-dimensional, multilayer, sigma-coordinate hydrodynamic Princeton Ocean Model (POM). The basic model code includes the hydrodynamic equations for conservation of mass, momentum, temperature and salinity, coupled by an equation of state, while a second moment turbulence closure model provides for realistic turbulent mixing. The model was initially developed by Blumberg and Mellor (1983) and has been modified by Kourafalou et al. (1996a) to include a parameterisation of plume dynamics. A source term was added in the continuity equation and the riverine input is represented in a way that directly affects the free surface elevation and the resulting vertical velocity near the river mouth. The only parameter that needs to be specified is the amount of freshwater discharge, i.e. water of zero salinity. The value of salinity near the mouth is thus, time and space varying and is determined according to the mixing conditions. The horizontal mixing depends on the grid size and the velocity field, as the horizontal eddy viscosity / diffusivity parameter is given by the Smagorinsky formula. The vertical eddy viscosity / diffusivity parameter is calculated according to the Mellor and Yamada (1982) turbulence closure scheme. The model can successfully represent the dynamics of a freshwater plume, as was shown in previous studies of river plumes in semi-enclosed Mediterranean basins (Kourafalou, 1999, 2000) and in the open ocean (Kourafalou et al., 1996b).

The present application has realistic bathymetry for the Black Sea and an open boundary at the line between the West and East Black Sea (Fig. 1), thus covering the area between approximately $41^{\circ} \mathrm{N}$ and $47^{\circ} \mathrm{N}, 28^{\circ} \mathrm{E}$ and $33.5^{\circ} \mathrm{E}$. The horizontal resolution is $10 \mathrm{~km}$ by $10 \mathrm{~km}$, and 16 layers are set vertically. We feel that for the purposes of the present study, resolution is adequate and eddy permitting; a better resolution is envisioned in future applications with high frequency forcing for the full resolution of the eddy field. We concentrate on shelf dynamics, neglecting any interaction with the overall basin circulation and exchange with the Mediterranean. We impose a radiation-type boundary condition for the velocities at the open boundary and we keep the Bosphorous mouth closed. The initial and boundary conditions for temperature and salinity employ monthly and annual mean values. This climatic data set is based on more than 25000 stations in the last 70 years and is described by Altman et al. (1987).

\section{The numerical simulation}

One of the most delicate parts in numerical simulations of coastal circulation is the imposed wind stress forcing. Particularly in climatological studies, the winds are usually taken from large-scale atmospheric models that often lack the desired resolution and are not quite representative of the local atmospheric conditions. Particlularly in the Black Sea, where the year round stratification creates an upper layer that may be viewed as detached from the deeper layers, it is obvious that details in the wind forcing are of great importance. We adopt here the data set of Staneva and Stanev (1998). They have examined various climatological wind data sets and they have incorporated additional data from ship observations to prepare a new data set that is downscaled and representative of the local basin dynamics, including the shelf area. An example of the wind data set ( 1 deg by $2 / 3$ deg in resolution), imposed on the model grid is shown in Fig. 2 for the months of April and December. The intense seasonal variability is evident, with April characterised by light northeasterlies to easterlies (maximum values reach $\sim 5 \mathrm{~m} / \mathrm{s}$ ), while December exhibits much stronger winds (up to $\sim 15$ $\mathrm{m} / \mathrm{s}$ ) with the predominant direction on the western part of the shelf coming from North and Northwest. During the simulation, the wind changes at the middle of each month, yielding a weighted influence from two consecutive months.

The adopted climatic values of river runoff for the Danube, Dnestr, Bug and Dnepr rivers are shown in Fig. 3. The monthly mean data for river discharge are taken from Altman and Kumish (1986) and are further prepared and analysed by Staneva and Stanev (1998). The intense seasonal variability is evident here, as well as maximum runoff during the late spring to early summer periods. It is obvious from Fig. 3 that the Danube runoff far exceeds that of the other rivers, reaching as high as $10000 \mathrm{~m}^{3} / \mathrm{s}$ during the peak season. This reflects the enormous drainage area for the Danube and puts it in the same category as the Amazon and the Mississippi, i.e. rivers with extreme discharge values. Therefore, we mainly discuss the development and evolution of the Danube River plume in this paper, as the dominant marker of transport of terrestrial inputs in the Black Sea under the influence of atmospheric forcing. The three other rivers are also significant, however, and their contribution is taken into account.

At first, we examine the flow field that is caused by imposing water of zero salinity at the coastal model nodes that correspond to the river mouths. An annual mean value of runoff is specified for each river. The atmospheric input is ignored, so that the only external input is river discharge and the resulting flow is largely buoyancy-driven, i.e. due to the salinity difference between riverine and ambient waters. The dynamics of the formation and evolution of the river plume have been discussed in detail in applications with the same model (as in Kourafalou et al., 1996a). For this experiment, initial conditions were homogeneous fields of temperature $\left(12^{\circ} \mathrm{C}\right)$ and salinity (18 psu). Figure 4 depicts the model computed near-surface salinity patterns after 30 days of simulation for (a) realistic topography and (b) flat bottom of $20 \mathrm{~m}$. A band of low-salinity water, bounded by the 17.5 psu line, has been formed along the coast and near the river area. This is the result of the merging of the individual river plumes. The most impressive formation is naturally near the Danube delta. The anticyclonic offshore bulge that is characteristic of a river plume (Chao, 1988; Kourafalou et al., 1996a) is pronounced and the southward coastal current is formed immediately south of the delta, as a balance between the cross-shore pressure gradient and the along-shore compo- 

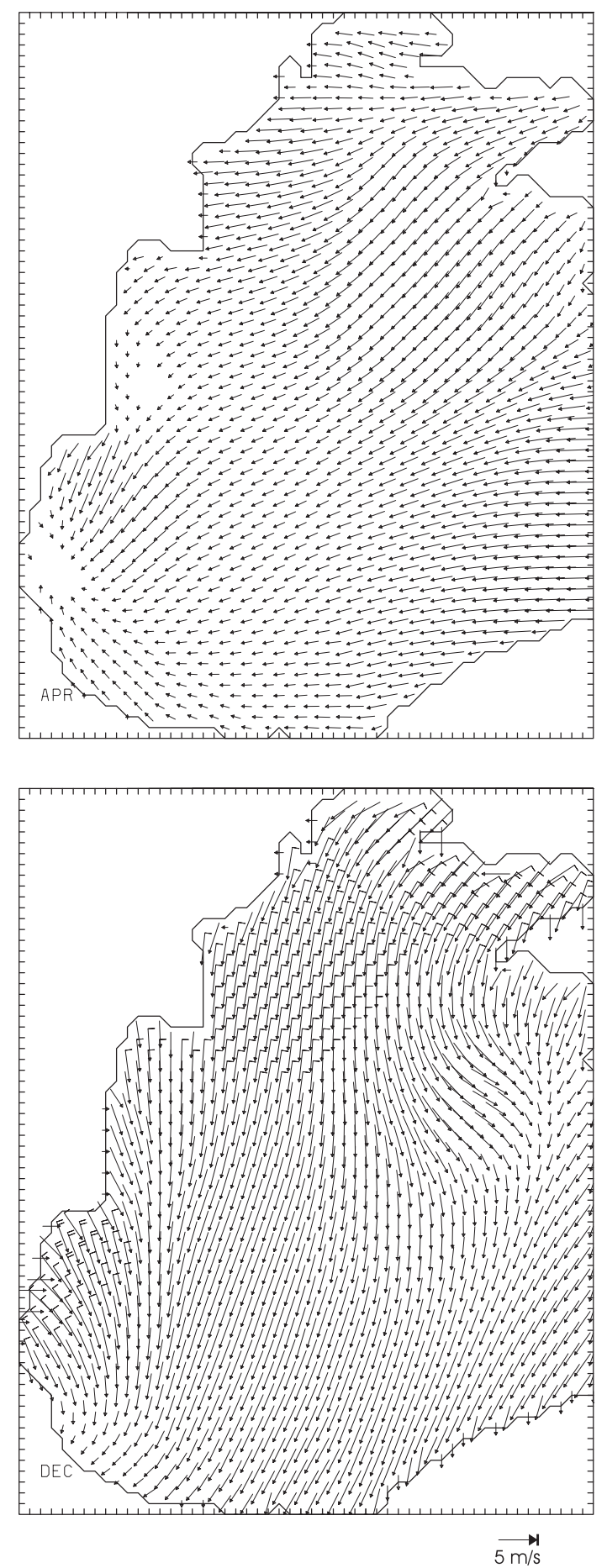

Fig. 2. Wind vectors for April (upper panel) and December (lower panel), interpolated on the model grid.

nent of the Coriolis force. These patterns are more prominent in Fig. 4a, as compared to Fig. 4b, a result that underlines the role of topography in forming the coastal circulation patterns. Also seen in Fig. 4 are smaller plumes associated with the other rivers and a tendency for southward flow along most of the nearshore area of the NWS. The multiple cells of anticyclonic circulation within the Danube River plume offshore
MONTHLY RIVER DISCHARGE (m3/s)

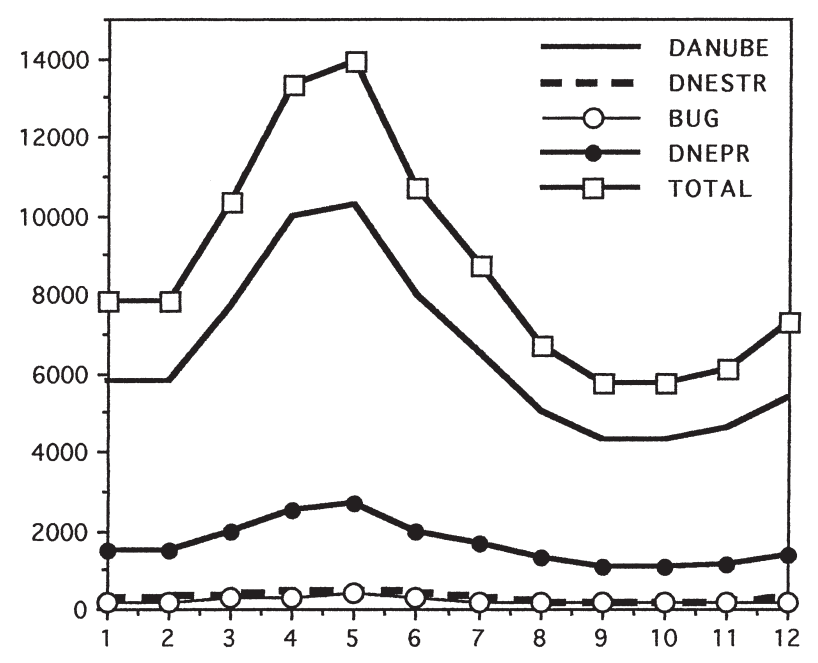

Fig. 3. Monthly discharge for the Black Sea rivers.

bulge are due to the very high runoff. A twin experiment, but with the Danube runoff reduced to $1 / 4$ of the annual mean value, depicts a uniform anticyclone within the bulge. The reduction in river runoff weakens the buoyancy forcing, but the plume characteristics remain the same. The flow within the plume is largely expressed as an anticyclone near the river mouth (similar to the findings of Ivanov et al., 1996) and a southward coastal current. This current depicts the combined result of the Danube and the neighboring rivers, i.e. it is the predominant flow within the low salinity band.

A similar experiment was performed, but with the Danube plume only. The resulting flow field had minor changes, namely a somewhat reduced coastal current and a slight northward flow. The former is due to the lack of contribution from the other rivers. The latter is due to a balance between the along-shore pressure gradient (due to the salinity difference between riverine and ambient waters north of the river mouth) and the alongshore local acceleration. As discussed in Kourafalou et al. (1996a), this flow regime is weak and, in contrast to the predominant southward current, non-geostrophic, the cross-shore Coriolis force is zero, due to the so-called "coastal constraint" (i.e. no cross-shore flow near the coast). The offshore expansion of the Danube River plume was also slightly enhanced. We performed several experiments with the Danube River input alone and with idealised buoyancy and wind forcing. We found that the favorable conditions for substantial offshore removal of low salinity waters from the Danube River delta include upwelling favorable winds after prolonged periods of low wind stress. An example is shown in Fig. 5, where constant winds from the Southwest (speed of $8 \mathrm{~m} \mathrm{~s}^{-1}$ ) are imposed for five days after a 40-day simulation with conditions similar to the previous experiment (constant discharge and no wind). The strong offshore expansion of low salinity waters is evident in Fig. 5b, while small "lenses" of lowest salinity waters can be seen away from the delta, revealing a transport mechanism that is 

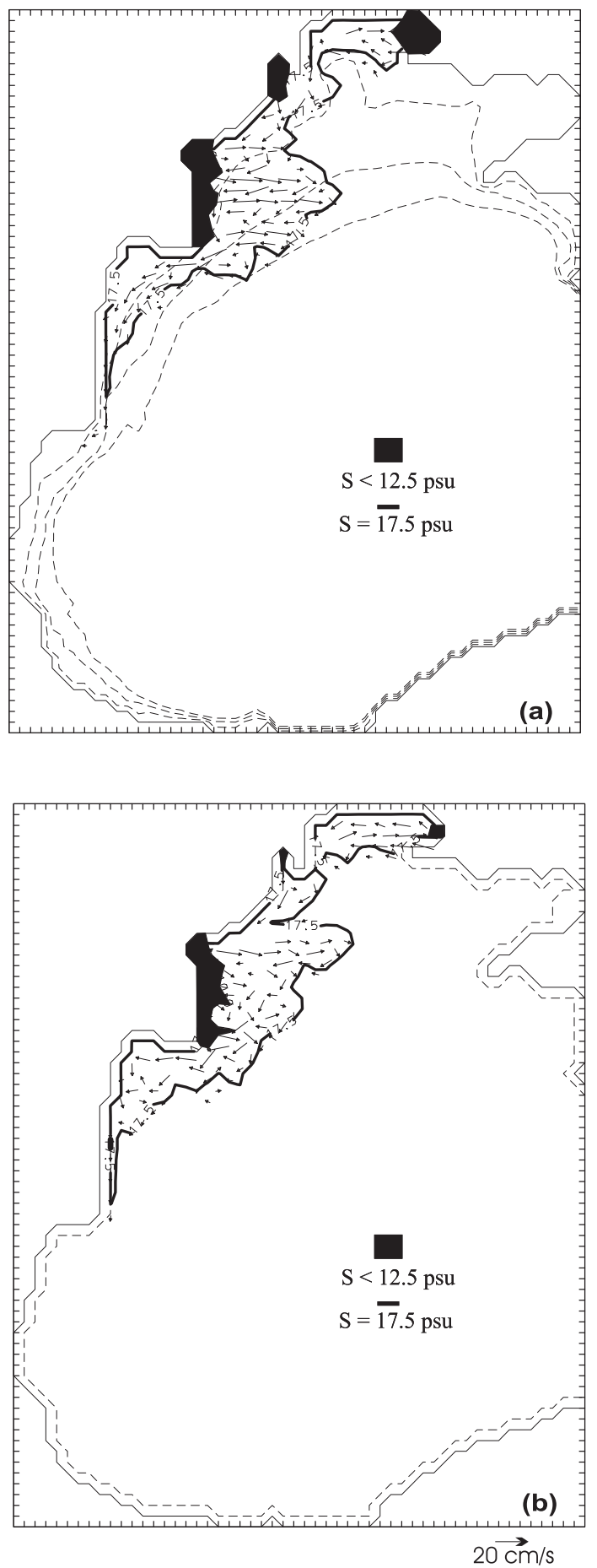

Fig. 4. Model computed near-surface salinity and current velocity for the buoyancy-only numerical simulation, after 30 days and for (a) topography as in Fig. 1 (dashed lines are the $20 \mathrm{~m}, 40 \mathrm{~m}$ and $60 \mathrm{~m}$ isobaths), (b) flat bottom at $20 \mathrm{~m}$. Black denotes lowest salinity water areas (less than $12.5 \mathrm{psu}$ ) and the boundary is marked by the 17.5 psu line.

characteristic during upwelling favorable winds (Kourafalou et al., 1996b).

Next, we performed a full-forcing experiment adopting the
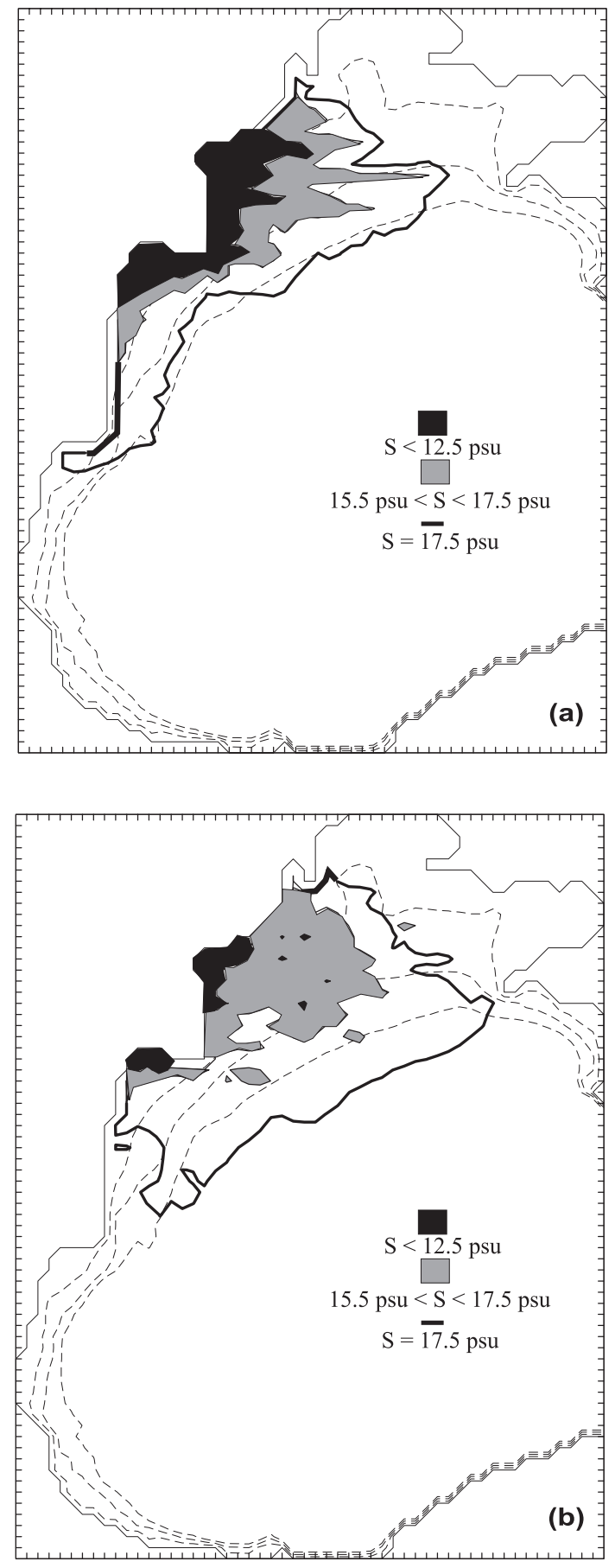

Fig. 5. Model computed near-surface salinity for the Danube only experiment; (a) after 40 days of buoyancy-only input and (b) after 5 more days with constant winds from the Southwest; dashed lines are the $20 \mathrm{~m}, 40 \mathrm{~m}$ and $60 \mathrm{~m}$ isobaths.

data sets described above for forcing, initial and boundary conditions. The simulation lasted two years with perpetual forcing. Here we analyse results from the second year of integration. We show monthly-averaged salinity fields. The 17 psu line was taken as the boundary between the coastal low-salinity band (CLSB) and the ambient shelf waters. 


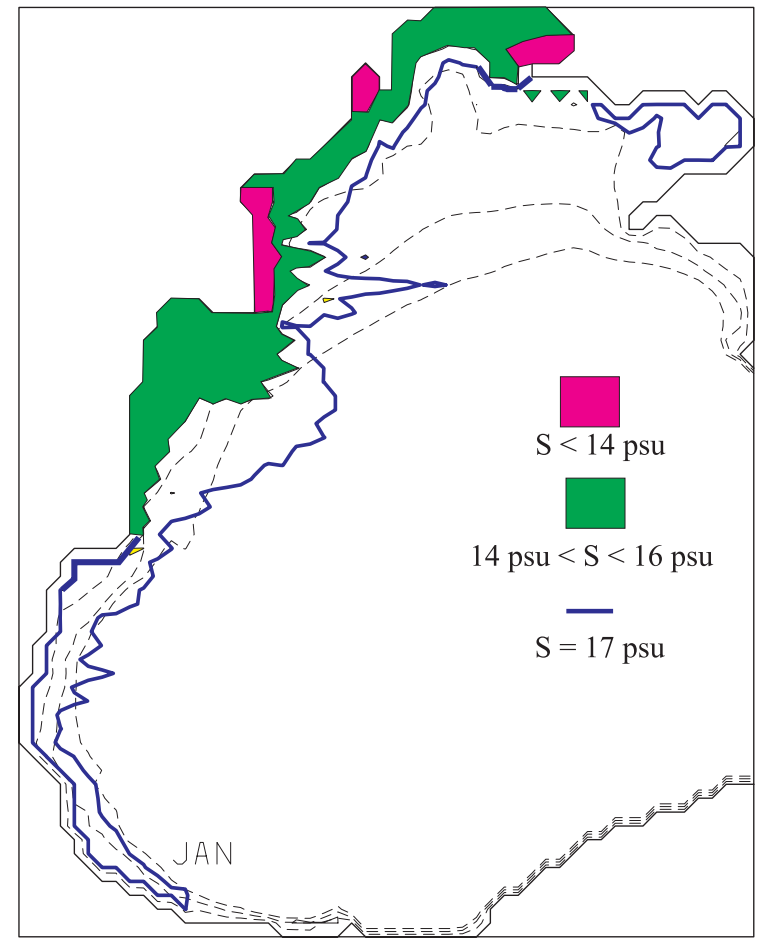

Fig. 6. Model computed near-surface salinity for the full, perpetual forcing, 2-year simulation for the month of January; dashed lines are the $20 \mathrm{~m}, 40 \mathrm{~m}$ and $60 \mathrm{~m}$ isobaths.

The January field (Fig. 6) has an elongated, relatively narrow CLSB, stretching all the way to the southernmost part of the NWS. This is due to the prevailing north-northeasterlies, which exhibit a similar pattern to that depicted in Fig. 2 for December. These winds have a strong downwelling-favorable component for the western coast of the NWS, thus encouraging the buoyancy-driven southward current. The coastal current has pronounced barotropic and baroclinic components and it transports low-salinity waters southward, far away from the sources. At the same time, offshore flow is restricted. A small amount of low-salinity water has been advected toward the Crimea peninsula, due to higher runoff in December and local winds that favored eastward advection.

A similar pattern continues through February, which is characterised by low runoff and downwelling-favorable winds. However, the magnitude of the wind stress starts to diminish, so the CLSB is retreating at the southern part of the domain. The CSLB exhibits a meandering pattern nearsurface (Fig. 7a), while small amounts of low-salinity water are found in the deeper layers (Fig. 7b), showing that wind stress has induced strong mixing with the saltier shelf waters.

By April (Fig. 8), larger amounts of low-salinity water can be found in the CSLB, due to the increasingly higher runoff and the lighter winds. These conditions continue during May, while the wind stress attains an upwelling-favorable component in the vicinity of the rivers (Fig. 2). These factors combine to give the distribution depicted in Fig. 9: a wide CSLB with large amounts of low-salinity waters both
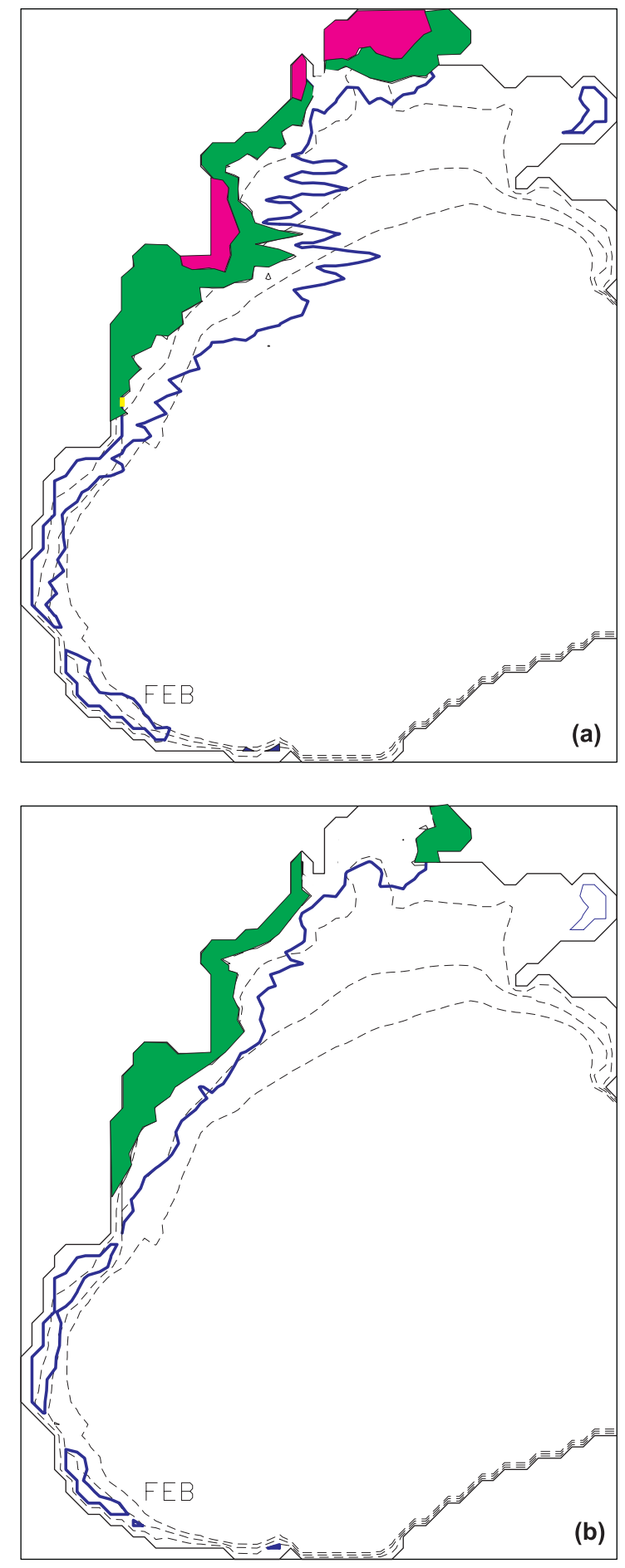

Fig. 7. Same as in Fig. 6, but for February and for (a) near-surface and (b) near-bottom.

at the surface (Fig. 9a) and near-bottom (Fig. 9b); strong offshore advection toward the Crimea peninsula and a considerable amount of very low-salinity water near-bottom at Dnepr, due to the locally onshore winds that induce strongest downwelling there.

June comes after the highest runoff and is characterised by 


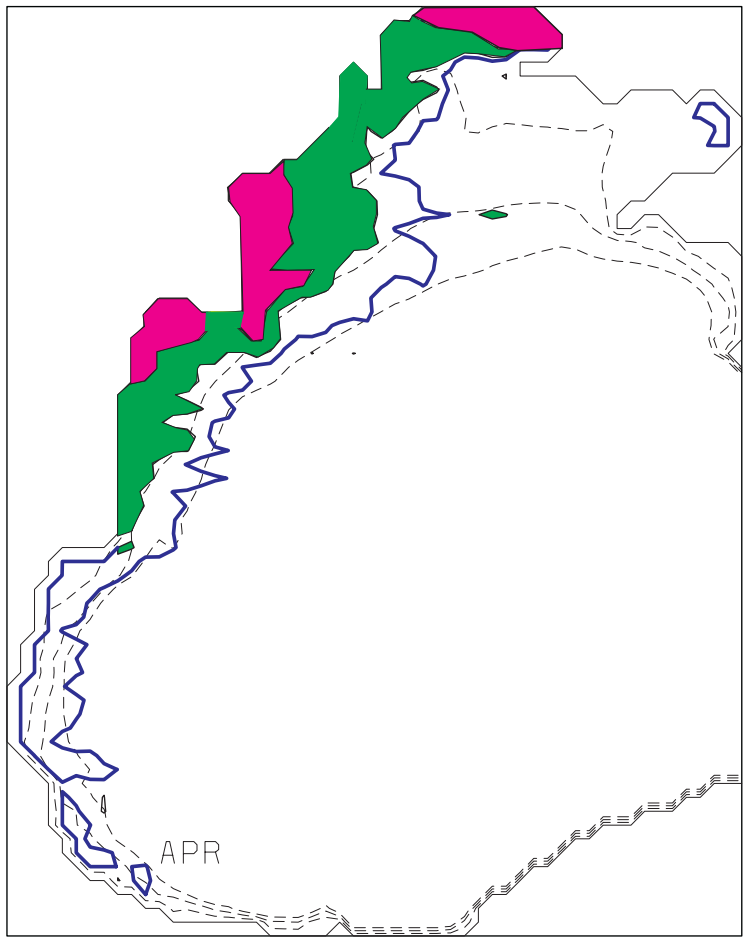

Fig. 8. Same as in Fig. 6, but for April.

southerlies and westerlies. Consequently, offshore extension of the CSLB is favored, while the large amount of brackish waters ( $S<14$ psu) is maintained (Fig. 10). Similar conditions continue through the rest of the summer. Runoff starts to drop in autumn, while winds start to pick up. A very interesting pattern takes place in October, when the strongest offshore removal of riverine waters can be found (Fig. 11). The southward extension of the CSLB has been greatly diminished, while this is the only month that the band actually reaches the Crimea peninsula. The wind field has the particularity of the strongest southerlies and westerlies (especially in the river area), while the water column is strongly stratified as wind stress has not yet attained the strong winter values. These conditions are most favorable for decoupling between "upper" and "lower" layers and offshore advection is particularly pronounced near the surface.

\section{Summary and discussion}

The numerical experiments focused on the influence of terrestrial and atmospheric inputs on the coastal dynamics of the NorthWestern Shelf of the Black Sea. The hydrodynamics are greatly influenced by the river runoff, which induces buoyancy-driven circulation. The interaction with the atmosphere is mainly viewed through the wind stress action, which acts as a transport agent for the low-salinity waters that form after the mixing of shelf and riverine waters. The Danube River plume dominates the coastal dynamics, due to excess runoff and the wide, smoothly sloping shelf in the vicinity of the river. A strong feature is the anticyclonic bulge near
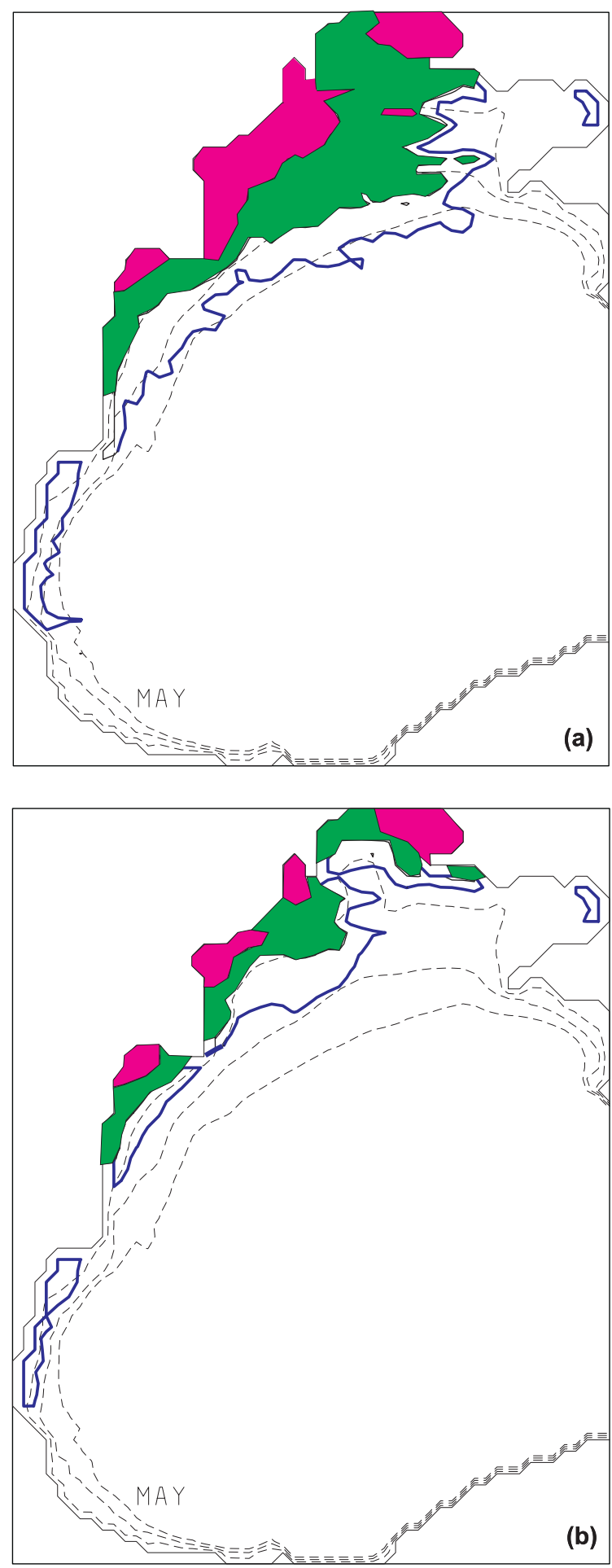

Fig. 9. Same as in Fig. 6, but for May and for (a) near-surface and (b) near-bottom.

the river mouth, that was particularly pronounced in the basic simulation, without wind forcing. This agrees with the findings of Ivanov et al. (1996); they attributed the anticyclone in front of the Danube mouth to a balance between non-linear terms and Coriolis, similar to the findings of numerous plume studies, as reviewed in Kourafalou et al. (1996a). Topogra- 


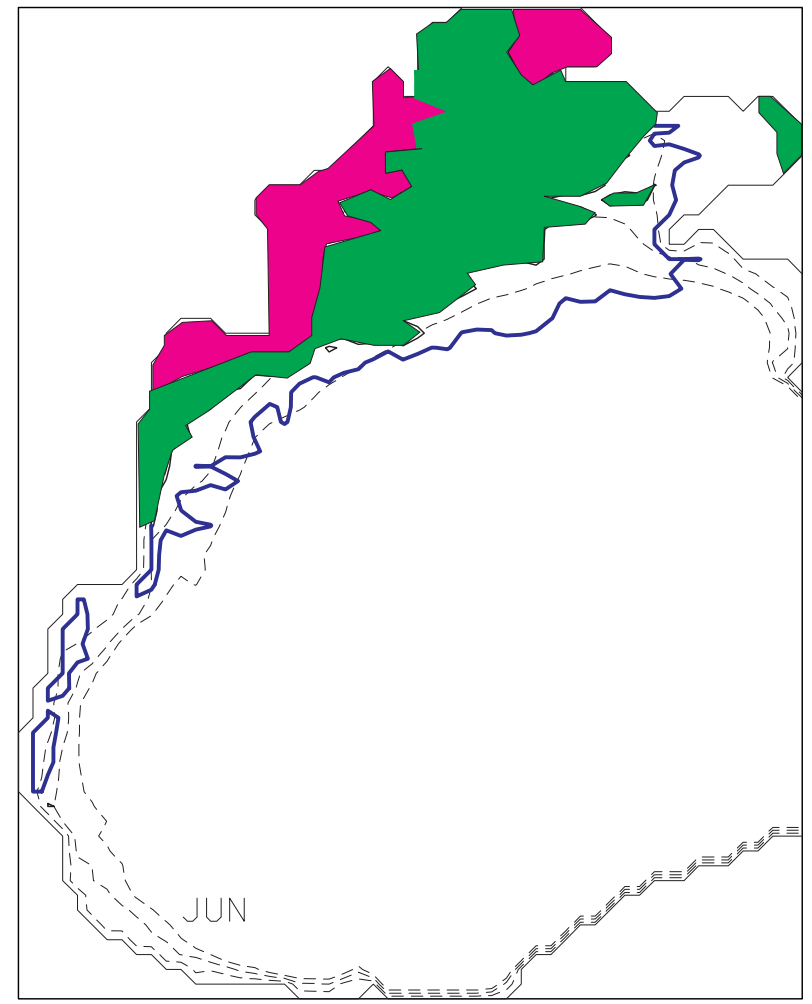

Fig. 10. Same as in Fig. 6, but for June.

phy allows for a broad offshore bulge in the vicinity of the Danube delta and a coastal current that is restricted in a narrow nearshore band.

The model shows that a Coastal Low Salinity Band is formed on the shelf due to the combined river input. This is a known feature for the NWS but also for the Black Sea at large, as it is known to influence the overall salinity structure. The baroclinic circulation on the NWS is dominated by the buoyancy induced southward coastal current, which controls the dominant pathway for the removal of river-borne waters and hence, associated materials. However, it is found that the magnitude and direction of wind stress can have significant implications toward alternative pathways, such as the rapid offshore transport and removal toward the basin interior.

In general, the induced circulation exhibits strong seasonal variability, following the changes in the forcing mechanisms. Spring (March-April-May) has the strongest runoff and the lowest wind stress. The CSLB extends mainly southward with offshore displacement starting in May. Large amounts of low-salinity waters are found near-bottom. Summer (JuneJuly-August) has large amounts of accumulated low-salinity waters and the most profound eastward displacement of the CSLB, due to upwelling-favorable winds. The wind stress starts to become stronger in the fall (September-October-November), while runoff is diminished, so that the offshore displacement of the CSLB slows down. An exceptional situation takes place during October, when substantial westerlies in the northwest part of the basin are responsible for strong

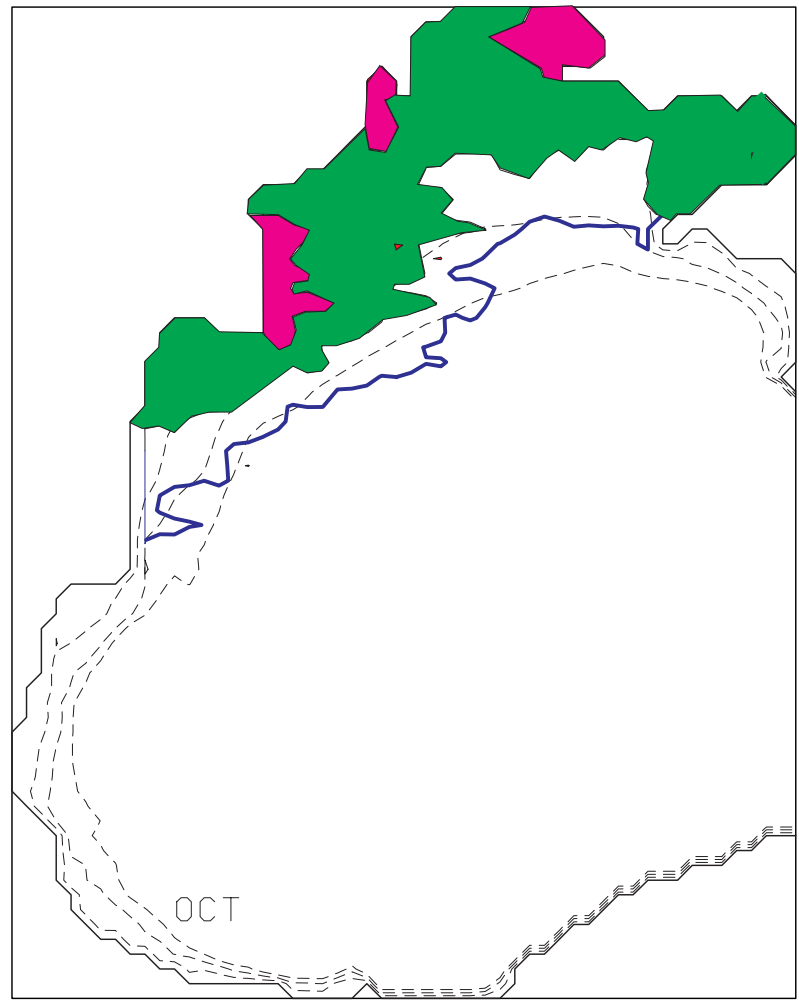

Fig. 11. Same as in Fig. 6, but for October.

eastward transport of riverine waters. Lowest runoff and strongest wind stress in winter (December-January-February) combine to give the maximum southward transport of lowsalinity waters and the narrowing in the width of the CSLB. Toward the end of the winter (February), when the downwelling-favorable winds start to diminish, the computed meandering pattern resembles similar findings for wind relaxation periods that have been attributed to a baroclinic instability process in Oey and Mellor (1993) and Kourafalou et al. (1996a).

Seasonal variability is evident from data, although it is hard to compare survey observations to climatological model runs for validation of the study findings. We present data derived, near-surface, salinity patterns (Fig. 12) obtained under the Co-operative Marine Science Black Sea (CoMSBlack) program (Oguz et al., 1993, 1994; Ozsoy and Unluata, 1998). These data have been obtained from three quasi-synoptic surveys during 2-29 September 1991, 4-26 July 1992 and 2-14 April 1993. Their analysis gives very detailed information about the water structure, both in the horizontal and vertical direction, and they support the present results by showing the dominance of river runoff in the seasonal shelf variability. The lowest salinity reaches $11 \mathrm{psu}$ in spring and $13.5 \mathrm{psu}$ during late summer and fall. These values are in close agreement with the model findings. A well-defined front separates coastal and offshore waters and the 17 psu line denotes it; this corresponds to the CSLB discussed here. In general, the observed patterns of salinity give support to the idea that the 

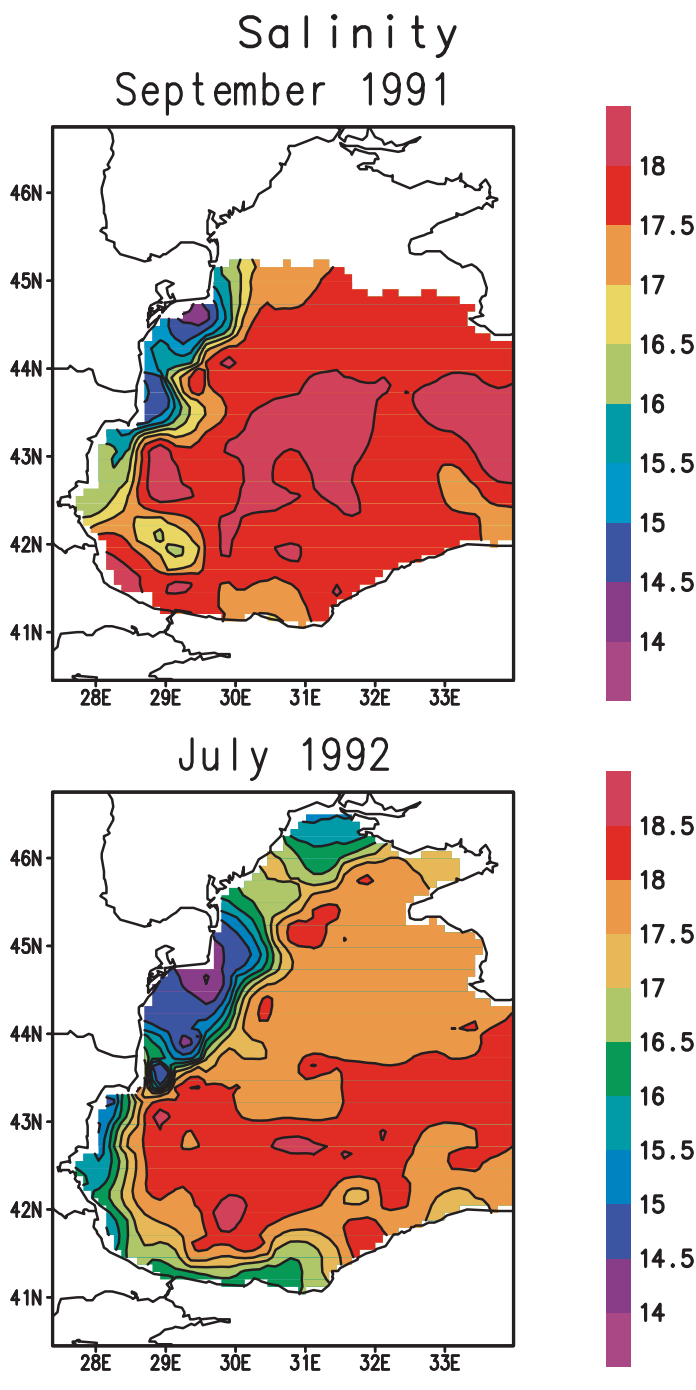

April 1993

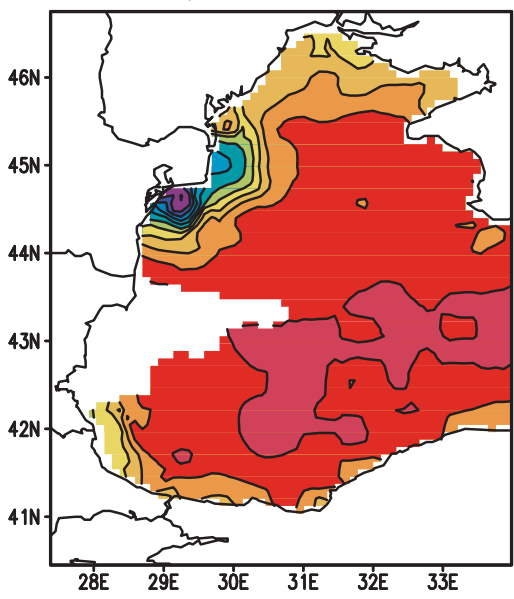

Fig. 12. Data derived near-surface salinity for the three survey periods.

circulation in close proximity to the river delta is dominated by river plume physics. Synoptic-scale changes in the shape of the plume are attributed to the local dynamics and forcing
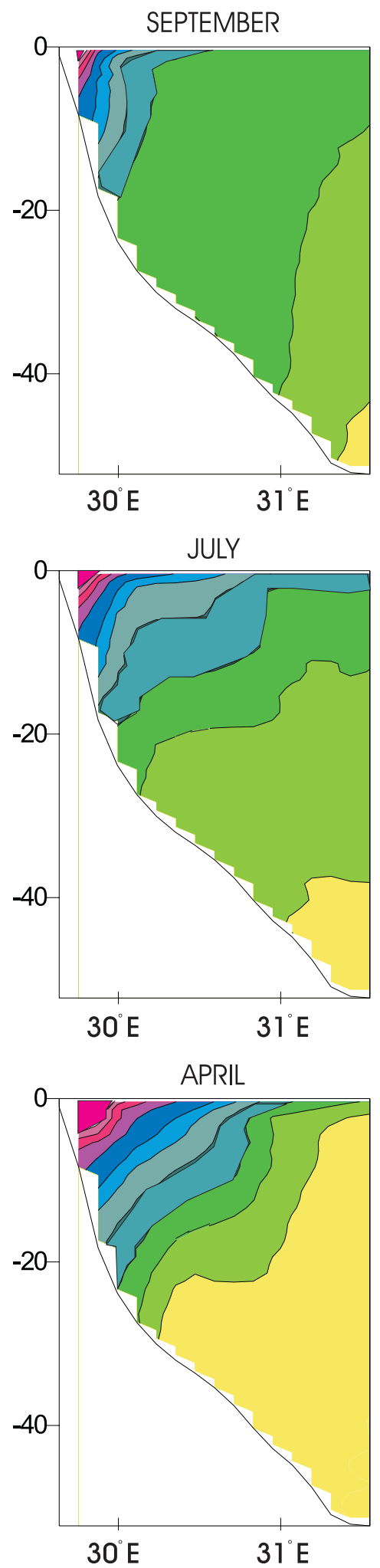

$31^{\circ} \mathrm{E}$

Fig. 13. Model derived cross-sections of salinity at $45^{\circ} \mathrm{N}$ and for the months of September, July and April.

conditions, and offer preliminary validation of model results.

For a better comparison, we computed cross-sections of 


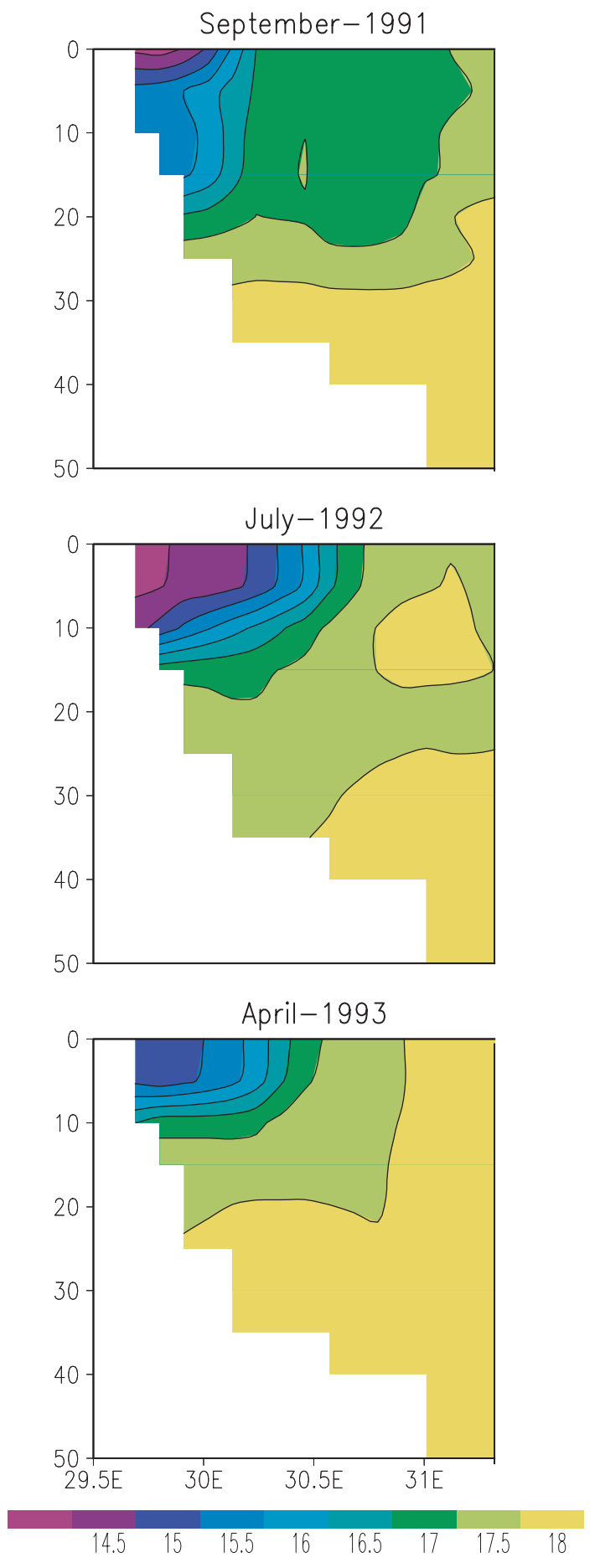

Fig. 14. Data derived cross-sections of salinity at $45^{\circ} \mathrm{N}$ and for the months of September 1991, July 1992 and April 1993.

salinity at $45^{\circ} \mathrm{N}$, across the Danube delta, for model results (Fig. 13) and for the data (Fig. 14). The model patterns are monthly averages for the same months as the data surveys. We caution that such a comparison is difficult, as the model results are in the climatological sense, while the data derived patterns include the episodic nature of the wind stress and buoyancy forcings. However, certain interesting remarks can be drawn. The core of the plume (salinity less than 16.5 psu) occupies the upper part of the water column, where it is deepest in September, for both model and data. Vertical stratification is diminished in September, as compared to July, with lowest salinity waters confined near the coast, while low-salinity waters of between 16.5 psu and 18 psu extend farther offshore. The maximum volume of brackish waters (salinity less than $15 \mathrm{psu}$ ) is shown for April, by the model, and for July, by the data. The plume is shallowest in April in both Figs. 13 and 14, with the model exhibiting more tilted isohalines, as compared to the data. The maximum vertical stratification takes place in July, for both model and data derived distributions.

Another qualitative comparison can be obtained with longterm averaged remote sensing data obtained using CZCS (Barale and Murray, 1995). These data give an illustrative evidence of plume variability, as the pigment can be closely related to riverine inputs. We present 7-year averaged distributions (1979-1985) in Fig. 15. These data show that the CSLB waters usually take a southward path, but often are displaced to the north, or intrude toward the shelf interior. The seasonal change in width of the CSLB agrees with the model findings. Quite interestingly, the data also show that October is exceptional, as it is the only month that the CSLB reaches the Crimea peninsula. This comparison offers encouragement on the accuracy of the atmospheric data set, which gives the right spatial and temporal variability.

The present study shows that the effect of riverine waters on the circulation of the NWS is of primary importance. One can use the brackish waters as a marker for the pathways of terrestrial inputs introduced in the NWS by the rivers. The numerical simulations lead to the conclusion that it is the interplay between buoyancy, wind stress and topography that creates the different patterns. Consequently, seasonal and inter-annual variability in the two forcings has a strong influence on the transport and fate of the terrestrial inputs. Furthermore, consequences in the overall basin hydrography can be detected, as the conditions on the NWS directly affect the upper part of the basin waters.

The present model has given reliable seasonal patterns of the transport of riverine low-salinity waters and associated materials. More comprehensive numerical experiments are under way, in order to take into account the interaction between shelf and deeper parts in the Black Sea, and between the physics and the biogeochemistry. The goal is to contribute toward the understanding of the processes that influence the long-term changes in the hydrological and ecological characteristics of the basin, which have been attributed to significant changes in river inputs.

Acknowledgements. V. Belokopitov has kindly made the data from the CoMSBlack cruises available to us. We thank Joanna Staneva for the preparation of data derived figures and two anonymous reviewers for their comments.

Topical Editor N. Pinardi thanks T. Oguz and another referee for their help in evaluating this paper. 

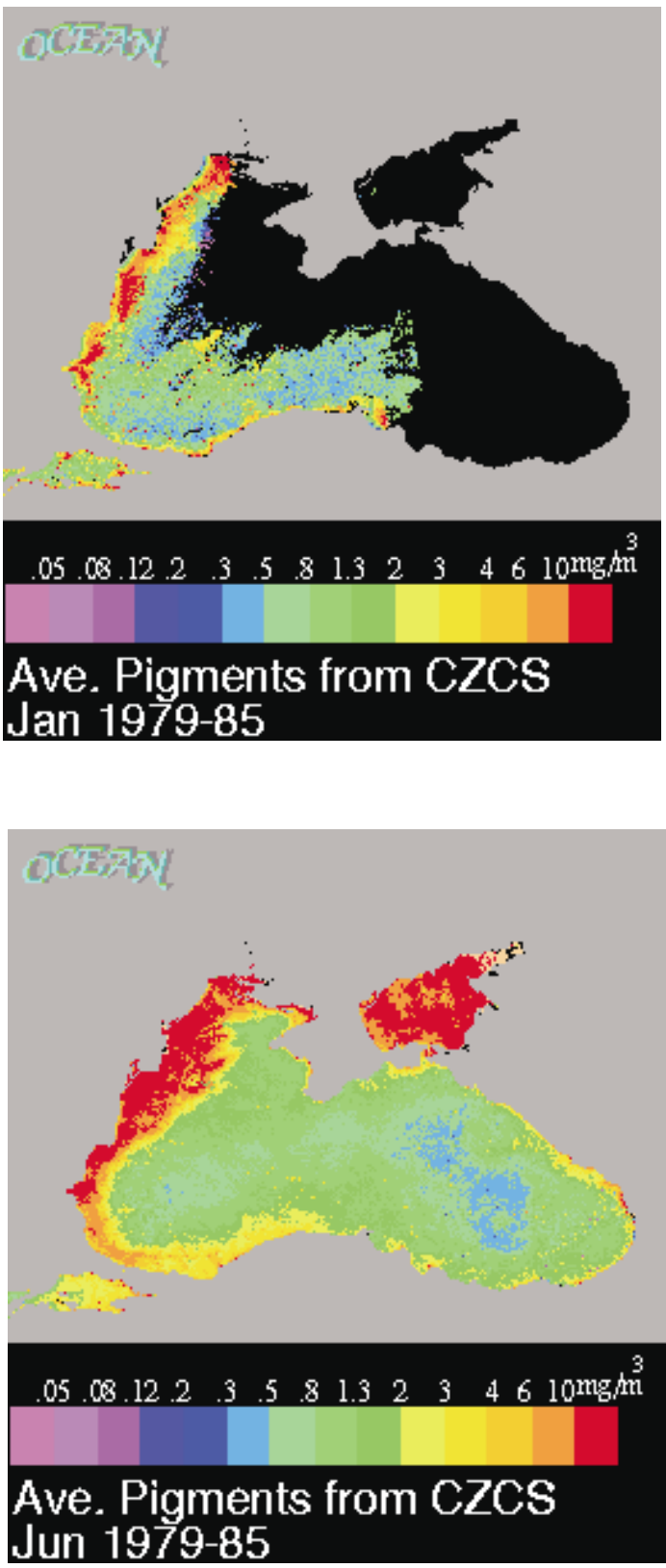
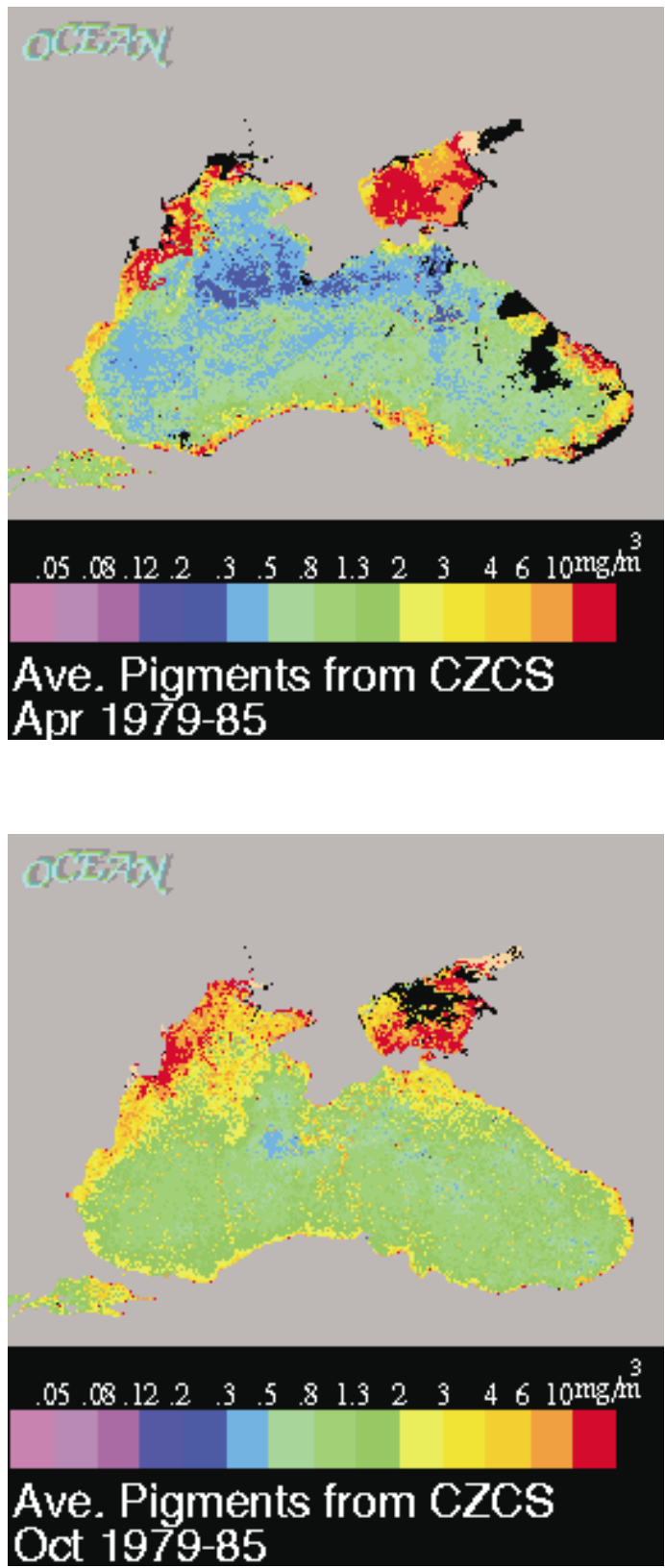

Fig. 15. CZCS derived pigment, 7-year averaged distributions (1979-1985).

\section{References}

Altman, E. N. and Kumish, N. I., Interannual and seasonal variability of the Black Sea fresh water balance, Trudy Gos. Oceanogr. Inst., 145, 3-15 (in Russian), 1986.

Altman, E. N., Gertman, I. F., and Golubeva, Z. A., Climatological fields of salinity and temperature in the Black Sea, Report, 109pp, State Oceanogr. Inst., Sevastopol, Ukraine (in Russian), 1987.

Barale, V. and Murray, C. N., The surface color field of enclosed marine basins: Pigment patterns of the Black sea, Remote Sensing Reviews, 12, 61-82, 1995.

Blumberg, A. F. and Mellor, G. L., Diagnostic and prognostic numerical circulation studies of the South Atlantic Bight, J. Geophys. Res., 88(C8), 4579-4592, 1983.
Chao, S.-Y., River-forced estuarine plumes, J. Phys. Oceanogr., 18 72-88, 1988.

Ivanov, V. A., Kubryakov, A. I., Mikhailova, E. N., and Shapiro, N. B., Modelling of river outflow freshening effect during spring flood at the Black Sea northern shelf, Atm. Ocean Physics, 32, 152-160 (in Russian), 1996.

Kourafalou, V. H., Oey, L.-Y., Wang, J. D., and Lee, T. N., The fate of river discharge on the continental shelf, Part I: modeling the river plume and the inner-shelf coastal current, J. Geophys. Res., 101 (C2), 3415-3434, 1996a.

Kourafalou, V. H., Oey, L.-Y., Lee, T. N., and Wang, J. D., The fate of river discharge on the continental shelf, Part II: transport of coastal low-salinity waters under realistic wind and tidal mixing, J. Geophys. Res., 101 (C2), 3435-3455, 1996b. 
Kourafalou, V. H., Process studies on the Po River plume, North Adriatic Sea, J. Geophys. Res., 104 (C12), 29963-29985, 1999.

Kourafalou, V. H., Modelling river plumes on Mediterranean shelves: Po River plume (North Adriatic Sea) and Axios River plume (North Aegean Sea), J. Marine Syst., accepted, 2000.

Mellor, G. L. and Yamada, T., Development of a turbulence closure model for geophysical fluid problems, Rev. Geophys. Space Phys., 20(4), 851-875, 1982.

Mikhailova, E. N. and Shapiro, N. B., Modelling of propagation and transformation of riverine waters on a northwestern shelf and in an abyssal part of the Black Sea, Phys. Oceanogr., 8(3), 169-177 (translated in English from the Russian language journal "Morskoi Gidtofizicheski Zhurnal"), 1997.

Oey, L.-Y. and Mellor, G. L., Subtidal variability of estuarine outflow, plume and coastal current: a model study, J. Phys. Oceanogr., 23(1), 164-171, 1993.

Oguz, T., Latun, V. S., Latif, M. A., Vladimirov, V. V., Sur, H. I., Markov, A. A., Ozsoy, E., Kotovshchikov, B. B., Eremeev, V. V., and Unluata, U., Circulation in the surface and intermediate layers of the Black Sea, Deep Sea Res. 40, 1597-1612, 1993.

Oguz, T., Aubrey, D., Latun, V., Demirov, E., Kolesnikov, L., Sur, H., Diaconu, V., Besiktepe, S., Duman, M., Limeburner, R., and Eremeev, V., Mesoscale circulation and thermohaline structure of the Black Sea during HydroBlack'91, Deep Sea Res., 41, pp. 603-628, 1994.

Oguz, T., Malanotte-Rizzoli, P., and Aubrey, D. G., Wind and thermohaline circulation of the Black Sea driven by yearly mean climatological forcing, J. Geophys. Res., 100, 6845-6863, 1995.

Oguz, T. and Malanotte-Rizzoli, P., Seasonal variability of wind and thermohaline-driven circulation in the Black Sea: Modeling studies, J. Geophys. Res., 101 (C7), 16551-16569, 1996.
Ozsoy, E. and Unluata, U., The Black Sea., in A. Robinson and K. Brink (Eds.), The Sea, Volume 11, John Wiley \& Sons Inc., pp. 889-914, 1998.

Polikarpov, G. G., Kulebakina, L. G., Timoshchuk, V. I., and Stokozov, N. A., ${ }^{90} \mathrm{Sr}$ and ${ }^{137} \mathrm{Cs}$ in surface waters of the Dnieper River, the Black sea and the Aegean Sea in 1987 and 1988, J. Environ. Radioact., 13, 25-28, 1991.

Rachev, N. H. and Stanev, E. V., Eddy processes in semienclosed seas: A case study for the Black Sea, J. Phys. Oceanogr., 27, 1581-1601, 1997.

Roether, W., Manca, B. B., Klein, B., Georgopoulos, D., Beitzel, V., Kovaevic, V., and Lucetta, A., Recent changes in Eastern Mediterranean deep waters, Science, 271, 333-335, 1996.

Stanev, E. V., Roussenov, V. M., Rachev, N. H., and Staneva, J. V., Sea response to atmospheric variability: Model study for the Black Sea, J. Mar. Syst., 6, 241-267, 1995.

Stanev, E. V., Staneva, J. V., and Roussenov, V. M., On the Black Sea water mass formation, Model sensitivity study to atmospheric forcing and parameterizations of physical processes, J. Mar. Syst., 13, 245-272, 1996.

Staneva, J. V. and Stanev, E. V., Oceanic response to atmospheric forcing derived from different climatic data sets, Intercomparison study for the Black Sea. Oceanologica Acta, 21(3), 383-417, 1998.

Stanev, E. V., Beckers, J. M., Lancelot, Ch., Le Traon, P. Y., Staneva, J. V., Peneva, E. L., and Gregoire, M., Coastal-open ocean exchange, Black Sea examples from survey, satellite data and modeling, Estua., Coast and Shelf Sci., Supplementary issue, in press, 2000.

Zodiatis, G., Advection of the Black Sea water in the North Aegean Sea, The Global Atmosphere and Ocean System, 2, 41-60, 1994. 